\title{
Extraction and Application of Eco-Friendly Natural Dye Obtained from Kitchen Waste: Big Onion Skin
}

\section{Wijayapala U.G.S.}

\author{
Department of Texile and Clothing Technology, University of Moratuwa, Sri Lanka \\ samu@uom.lk
}

\begin{abstract}
Dyeing is an ancient art which predates written records. It was practised during the Bronze age in Europe. Primitive dyeing techniques included sticking plants to fabric or rubbing crushed pigments into cloth. Those methods became more sophisticated with time and techniques using natural dyes from crushed fruits, berries and other plants, which were boiled into the fabric and gave light and water fastness (resistance), were developed (dyeing of textiles, practical action.

Environmental issues are becoming more crucial all over the world. Natural dyes due to their eco-friendly nature create a superior value to the textile substrate. With the advent of synthetic dyes in abundance and a wide range of colours of remarkable fastness properties made its way making natural dyes a past. The dyes extracted from natural sources like plant, animal and minerals are called natural dyes. Pharmaceutical, food and fruit industry wastes are one of the main sources of colourants which can be employed for textile coloration.

The onion (Allium cepa), also known as the bulb onion or common onion, is used as a vegetable and it is the most widely cultivated species of the genus Allium. Onion is most frequently a biennial or a perennial plant, but usually treated as an annual and harvested in its first growing season. The skin of the big onion contains a colourant which gives colouring component. Therefore extracts of waste big onion skin can be used to dye textiles to give better shades. As this dye is natural in origin it is eco-friendly dye suitable for green technology. In this way waste can be utilized for getting best.
\end{abstract}

Keywords: Big onion, Colourant, waste, Textile, Colouration 